\title{
Der Fiskalpakt - eine Sprosse auf der Integrationsleiter
}

VB verfassungsblog.de/der-fiskalpakt-eine-sprosse-auf-der-integrationsleiter/

Frank Schorkopf Fr 13 Apr 2012

Fr $13 \mathrm{Apr}$

2012

Die Bundesregierung hat den Entwurf eines Gesetzes zu dem Vertrag vom 2. März 2012 über Stabilität, Koordinierung und Steuerung in der Wirtschafts- und Währungsunion in den Deutschen Bundestag eingebracht. Mit dem Ratifikationsverfahren hebt nun auch eine Debatte über diesen Fiskalpakt an. Der Pakt steht mit Inhalt, Form und Kontext für die europäische Integration der Gegenwart. Die Mitgliedstaaten wollen durch inn in der Unionskrise das Euro-Währungsgebiet kräftigen, ihre Haushaltsdisziplin fördern und ihre Wirtschaftspolitiken besser koordinieren. Sie machen diesen Schritt aber ohne den Konsens aller Mitgliedstaaten. Sie weichen deshalb auf den klassisch völkerrechtlichen Vertrag aus und stellen eine für Europas politische Verfasstheit wohlmöglich entscheidende Weiche.

Der Logos des Paktes erschließt sich über ein Dokument des Auswärtigen Amtes. Es handelt von den integrationspolitischen Fortschritten, die erforderlich seien, um eine Stabilitätsunion zu schaffen. Nach dem Strategiepapier, das den Bundestagsabgeordneten bereits im Oktober 2011 zugegangen ist, müsse sich Deutschland vier Herausforderungen stellen, um „die gegenwärtige Staatsschuldenkrise im Euro-Raum dauerhaft zu überwinden“: Neben kurzfristigem Krisen-Management seien entscheidende Schritte hin zu einer „echten Stabilitätsunion“ zu unternehmen, d.h. es müsse „eine Kultur solider Haushaltsführung verbindlich und fest“ verankert werden. Bei der Errichtung einer solchen wirtschafts- und finanzpolitischen Stabilitätsunion stellten sich „Fragen der politischen Verfasstheit Europa in neuem Licht“; Europa müsse die Finanzverfassung gegeben werden, die es brauche.

Der Fiskalvertrag verkörpert einerseits das erfolgreiche Ergebnis dieser Strategie und steht andererseits für deren vorläufiges Scheitern. Das Scheitern liegt darin, dass es nicht gelungen ist, die konkreten Schritte hin zu einer Stabilitätsunion im Primärrecht zu gehen. Großbritannien und schlussendlich die Tschechische Republik haben sich entschieden, eine Änderung des AEU-Vertrages nicht mitzutragen. Es ist deshalb nur der Ausweg auf die intergouvernementale Ebene geblieben, d.h. ein klassisch völkerrechtlicher Vertrag zwischen den 25 beteiligungswilligen Mitgliedstaaten. Der Erfolg besteht darin, dass es der deutschen Europapolitik weitgehend gelungen ist, ihr materielles Konzept in Recht zu übersetzen und damit die bislang ad hoc gestaltete Krisenreaktion wieder zu rationalisieren. Der bestehende, durch das Sixpack ertüchtigte Stabilitäts- und Wachstumspakt wird ergänzt werden durch die völkerrechtliche Pflichten zu einer strikteren Defizitgrenze, quasi-automatischen Sanktionen bei Defizitverstößen, einen Rechtsweg zum EuGH und zu nationalen Schuldenbremsen. Außerdem besteht ein Junktim zwischen dem disziplinierenden Fiskalpakt und dem Finanzhilfen austeilenden Europäischen Stabilitätsmechanismus (ESM), der parallel in das Ratifikationsverfahren gegangen ist.

Für die Verfassungsmäßigkeit des Paktes entscheidend werden seine gesetzliche Einbindung in die innerstaatliche Willensbildung, besonders die angemessenen Beteiligungsrechte des Bundestages sein. Nach Ansicht der Bundesregierung benötige der Vertrag eine Zwei-Drittel-Mehrheit in Bundestag und Bundesrat, Art. 23 Abs. 1 Satz 3 i.V.m. Art. 79 Abs. 2 GG seien entsprechend anzuwenden. Die deutschen Regelungen über die Schuldenbremse würden völkerrechtlich bindend werden und könnten dadurch nicht mehr ohne weiteres geändert oder ergänzt werden. Dass die Bundesregierung auf den Fiskalvertrag also das deutsche Europaverfassungsrecht anwenden will, ist sehr bemerkenswert. Ein Seitenblick auf den ESM-Vertrag verdeutlicht das, handelt es sich doch um einen völkerrechtlichen Vertrag, auf den die Bundesregierung Art. 23 GG ausdrücklich nicht anwenden will. Sie führt über die Frage sogar einen Organstreit vor dem Bundesverfassungsgericht (2 BvE 4/11). In dem Verfahren vertritt die Bundesregierung die Ansicht, dass es sich beim ESM nicht um eine „Angelegenheit der Europäischen Union“ im Sinne des Art. 23 Abs. 2 GG handele. Wer diesen Standpunkt hat, der müsste konsequent die Auffassung vertreten, dass auch der Fiskalvertrag diese Voraussetzung nicht erfüllt. Vielleicht hat die Bundesregierung aber auch - wie im 
Verfassungsblog schon vermutet - politische Motive, sich auf die Zwei-Drittel-Mehrheit festzulegen, oder aber sie nimmt nur einen Urteilsspruch aus Karlsruhe vorweg.

Die Kernregelungen des Fiskalpaktes lassen keine Zweifel daran, dass es sich um einen Vertrag handelt, der die primärrechtlichen Normen zur Wirtschafts- und Währungsunion vertiefen und ergänzen soll. Die Formulierung ,in Angelegenheiten der Europäischen Union“ betont den weiten Sinnzusammenhang, in dem der Anwendungsbereich des Art. 23 GG steht, und bezieht jeden unionsbezogenen Sachverhalt ein. Der Europa-Artikel ist unmittelbar auf den Fiskalvertrag anzuwenden. Der Vertrag enthält, vom deutschen Standpunkt betrachtet, jedoch keine Regelung, die nicht bereits der geltenden Schuldenbremse oder den unionsrechtlichen Pflichten entspräche und insoweit von den deutschen Zustimmungsgesetzen zum Primärrecht nicht gedeckt wäre. Das Grundgesetz wird inhaltlich nicht geändert oder ergänzt, solche Akte werden auch nicht ermöglicht. Das tragende Argument einer Konstitutionalisierung der Schuldenbremse, die das Instrument dem verfassungsändernden Gesetzgeber entziehe, beruht auf einem Irrtum. Der Fiskalvertrag ist ein völkerrechtlicher Vertrag, der nach den allgemeinen Regeln des Völkervertragsrechts gekündigt werden kann. Der Fiskalvertrag enthält zwar kein Kündigungsrecht, er spricht aber auch nicht - wie der EU- und der AEU-Vertrag - aus, dass er auf unbegrenzte Zeit geschlossen sei. Es ist hinzuzufügen, dass der Fiskalvertrag nach der Verfassungsrechtsprechung sogar zu kündigen ist, wenn die Wirtschafts- und Währungsunion das Stabilitätserfordernis nicht mehr erfüllt. Nach dem Grundsatz der Völkerrechtsfreundlichkeit müsste der verfassungsändernde Gesetzgeber seinen Änderungswillen also lediglich aufschieben, bis der Vertrag wirksam beendet wäre.

Ein Grundproblem des ganzen Dossiers besteht darin, dass die europäische Rechtsgemeinschaft in der Staatsschuldenkrise an ihre Grenzen stößt. Die EU ist auf die Folgefähigkeit und Folgebereitschaft ihrer Mitgliedstaaten angewiesen. Die Folgefähigkeit beruht auf der Verwaltungskapazität, die im Fall Griechenlands offenkundig schwach ist, nicht nur bei der Steuer- und Finanzverwaltung, sondern auch bei der Grenzsicherung und im Asylsystem. Mit Blick auf die durchwachsene Bereitschaft, das geltende Unionsrecht bislang anzuwenden, darf trotz Sympathie für die Paktziele gefragt werden, ob der neue Vertrag in der nächsten Krise angewendet werden wird. Es sei an die Aussage eines ehemaligen Bundeskanzlers erinnert, der in einem Interview 2011 erklärte, dass wer die Kriterien des Stabilitätspakts als quasi von Gott gegeben hinnehme, in Krisenzeiten nicht mehr adäquat reagieren könne.

Die Mehrheit der Mitgliedstaaten könnte sich durch den Abschluss des Fiskalpaktes einer Vertiefungslogik verschrieben haben. Wenn der Integrationsverband nicht mehr einheitlich, als EU-27 für die Fortentwicklung seines institutionellen Rahmens steht, dann muss eine sich ankündigende Spaltung politisch lohnend sein. Die Vorzeichen für einen erneuten großen Sprung hin zu einer Europäischen Verfassung, hin zu einer Europäischen Politischen Union, sind deutlich sichtbar. In dem Augenblick, in dem die Mechanismen staatlicher Eigenverantwortung und damit die Idee politischer Selbstbestimmung in Teilen der EU versagen, ist das Rezept die Integrationsvertiefung. Die Finanz- und Schuldenkrise werden zu Sprossen auf der Leiter der europäischen Integration.

Frank Schorkopf lehrt Öffentliches Recht an der Georg-August-Universität Göttingen .

LICENSED UNDER CC BY NC ND

SUGGESTED CITATION Schorkopf, Frank: Der Fiskalpakt - eine Sprosse auf der Integrationsleiter, VerfBlog, 2012/4/13, http://verfassungsblog.de/der-fiskalpakt-eine-sprosse-auf-der-integrationsleiter/. 